\title{
Challenge and Application of Micro-lecture in College English Teaching
}

\author{
Honglei Wang \\ College of Foreign Studies \\ Shandong Technology and Business University \\ Yantai, China
}

\begin{abstract}
The rapid development and popularity of microlecture is exerting profound and far-reaching influence on traditional college English class. While it poses as a challenge to the traditional English teaching mode, it is of great significance to explore the application methods of microlecture in college English class so as to improve college English teaching and help to promote the reform of college English teaching.
\end{abstract}

\section{Keywords-micro-lecture; application; college English}

\section{INTRODUCTION}

Influenced by the information technology, the traditional way of learning is undergoing changes, from E-learning (Digital Learning) to M-learning (mobile learning) and the present U-learning (ubiquitous learning). Undoubtedly, the traditional face-to-face classroom teaching mode has been challenged as it's becoming increasingly difficult to meet the needs of today's young people in this digital era. Owing to the rapid development of information and globalization, micro-lecture is booming in recent years as a new mode of teaching and learning.

"Micro-lecture", first appeared in the successful use of 60-Second Course by professor LeRoy A. McGrew from University of Northern Iowa to popularize the knowledge of organic chemistry, and in the One-Minute Lecture (OML) proposed by T.P. Kee from the British Napier University[1]. The concept of micro-lecture was articulated by an independent instructional designer and e-learning consultant David Penrose from San Juan College of the state of New Mexico. David Penrose pioneered the one-minute microlecture and called it knowledge burst [2]. He argues that with appropriate assignments and discussion, micro-lecture can achieve the same effect as the traditional class. The most influential and popular micro-lecture learning platform is the non-profit Khan Academy founded by educator Salman Khan in 2006 with the aim of providing a free, world-class education for anyone, anywhere.

As an innovative teaching-learning approach, the idea of micro-lecture was first put forward in 2011 in China, and has aroused extensive discussion ever since. Integrated with Internet, information technology, and other educational and media resources, the micro-lecture teaching-learning mode aims to design and develop a series of online and mobile learning video courses to better illustrate the difficult and questionable points in a course. The interest and discussion surrounding the use of micro-lectures has continued to grow. According to the National Universities Micro-teaching Development Report (2016) by the National College Teachers' network training center, micro-lecture is referred to as "the tiny and exquisite cell in the courses of the new generation". Micro-lecture is innovative not only because its presentation form is different - from the traditional paperbased to the new micro video-based, but its service object and teaching objective also changed: from teacher-centered to learner-centered, and from improving traditional classroom teaching efficiency to promoting the learning mode and teaching mode reform. Therefore as a new product of the information age, micro-lecture will undoubtedly bring opportunities for classroom teaching reform, and it may also be revolutionary to the traditional classroom.

\section{PRESEnt College English Teaching In ChinA}

After years of continuous reform and innovation, college English class has experienced profound changes. A variety of teaching methods and styles have emerged. However, problems still exist. Especially in the information age, the contradiction between teachers and students in the classroom is still outstanding.

\section{A. Characteristics of College Students' English learning}

College students have better autonomous learning ability and learning strategies. But it is found that students of different majors and genders have different learning beliefs and learning strategies in learning English. To begin with, college students possess stronger independent learning ability. Compared with high school students, college students show greater awareness of autonomous learning and autonomous learning ability. To be more specific, they prefer to study alone and they show stronger learning motivation and better abilities to make good use of learning recourses on the internet. In general, college students are more determined to achieve their goals by adopting practical and efficient learning strategies.

In addition, students of different majors and genders show different characteristics in learning English. According to a survey, language learning beliefs of the liberal arts group were more positive than that of the science students, and the 
use of learning strategies was better than that of science students. Meanwhile, male and female learners show obvious difference in English learning beliefs, learning strategies, judgment of the degree of difficulty in learning and their academic achievements. In fact, girls emphasize the importance of teachers and teachers' encouragement and evaluation in their learning, while boys tend to rely more on their mother tongue.

\section{B. Characteristics of College English Learning in China}

Currently three kinds of teaching modes are adopted and remain popular in College English teaching: the teachercentered teaching mode, the learner-centered teaching mode and the teaching mode that take the learners as the center and the teacher as the leading role.

It is true that college English teaching in China has undergone a long time of challenge and reform especially during the last 20 years. The key point is, however, no matter which part--he learner or the teacher or both, are taken as the center, the traditional classroom teaching neglects the individual differences shown either by different majors or genders. All learners are made to sit in the same classroom, studying the same textbooks at the same pace by the same approach. The academic disadvantaged groups can not be ignored and avoided. On the contrary, they should be fully respected and given more attention to in our teaching. But the truth is that college English teaching in China is based on large classes, ignoring individual differences and personalized learning. Student evaluation mainly depends on their examination performance with little attention given to process assessment. The ignorance of the students' initiative and individual differences in English learning leads to the poor teaching effect in college English.

\section{APPLiCATION OF MicRO-LECTURE IN TEACHING}

A micro-lecture is short, flexible, interesting and easy to share, which makes it a new way to promote the college English teaching reform. As a newly emerging teaching mode, research on micro-lecture is not profound or in-depth so far. Interestingly, the development of micro-lecture is largely due to various micro-lecture contests and events held in the recent few years which have drawn great attention of teachers and educators. Take the most influential National Universities Micro-Teaching Competition for example, the National Universities Micro-teaching Development Reports issued after each competition summarize the historical background of micro-teaching, the current situation, process, hotspots, trends and problems of micro-teaching in our domestic colleges and universities, which serves as valuable reference for the development of micro-teaching in college English. According to the reports, college English, as a public course, has the right qualities for the application of micro-lectures in its teaching and the entries have received very positive feedbacks. Again, a large number of outstanding foreign language micro-lecture works emerged in the Micro-course Contests of Foreign Languages in China, which provides valuable resources and reference for the production, construction and development of micro-teaching in College English.
It could be seen from the micro-teaching contests that micro teaching has broad prospects in English teaching. First, combined with traditional teaching mode, micro-lectures, presenting in the forms of micro video, micro animation and micro exchange, focus on the difficulties of the traditional classroom teaching. In this way, important and difficult points are able to be imparted to the learners through very brief explanation, which serves as a good choice for fragmentation learning. At the same time, classroom teaching also take diverse and rich forms.

Next, micro-lectures have the characteristics of being vivid and novel, theme prominent, short and interactive, which appeals more to the students. In contrast, the traditional classroom, whether it is indoctrination or discussion, inevitably falls into complicated and boring grammar and vocabulary explanation.

What's more, being mobile and easy to share, microlecture makes it more convenient for the autonomous learning of English. Acquisition of language can not only be achieved from classroom teaching. Micro-lectures provide more possibilities for learning English, making it easy for the students to study in fixed locations like the classroom, library, and watch online or download from the Internet for later independent learning. Besides, micro-teaching makes it convenient for the learners to exchange and discuss about their studies on the online platform.

Finally, micro-teaching is more interactive. The opening and sharing of micro-lectures not only means sharing micro video, but also a micro platform for discussion and interaction between the teacher and the learner. It is easier for the students to upload questions onto the micro platform, giving feedbacks to the teacher; the teacher can thus answer the questions, solve the problems and then modify and perfect their work. In this way, interactive teaching is truly realized [3].

\section{StRATEGIES FOR COLLEGE ENGLiSH Micro- TEACHING}

Driven by a number of micro-teaching contests and partly due to the popularity of MOOC and flipped classroom, micro-teaching has gradually become a focus in the field of college English. Meanwhile, open sharing curriculum resources have been paid unprecedented attention. But a micro-course is definitely not a simple collection of scattered and disorganized micro videos. To achieve its sustainable development in college English teaching, micro-teaching, which is handy and convenient for fragment learning, must be incorporated into the whole college English curriculum system, supported by a complete curriculum structure, micro-teaching plans, a micro-course platform for interaction and reasonable micro-lecture evaluation standards.

\section{A. Suppotive Policies}

Applying information technology to classroom teaching is a trend, and also a direction of reform in classroom teaching. The production and development of micro-lectures need advanced information and network technologies. What's more, a good micro-lecture also needs to be 
artistically appealing. This means that teachers need to update their ideas of teaching, and make efforts to learn the new curriculum design, and advanced information technology. Currently colleges especially college English generally put more emphasis on research and less on teaching. So it is important to make policies that encourage college English teachers to receive micro-teaching training, to carry out the development, application and research of micro-teaching in various ways, to make micro-teaching a new form of evaluation and assessment of teachers. In this way, more teachers will be drawn to participate in the construction of the micro-courses to make contributions to the sustainable development of college English microteaching.

\section{B. Team-building}

Judging from various micro-lecture contests, we can safely conclude that micro-teaching is fit for foreign language courses. What is involved in a college English class is numerous and jumbled, covering from spoken English, grammar, culture to writing and translation. Though each part is vital for learning a language well, it is difficult to deal with every aspect deeply and thoroughly, often caring for this and losing that. To produce a series of micro-lectures which make independent learning easy may greatly alleviate the pressure of the classroom and meet the requirements of different levels of students.

But first of all it must be made clear that a micro-lecture is not the compressed traditional class, or a simple collection of isolated knowledge points. To make college English micro-lectures, we should actively study the law of English teaching under the digital condition, and combine professional knowledge with information technology. In reality, the production of a micro-lecture must go through various steps, including selection of a subject, design, development, testing, and the like. Thus teamwork is necessary and decisive to put college English teaching under the macro background of the overall teaching innovation and development. Usually a micro-course team composes of teaching designers, outstanding lecturers, art designers, photographers, nonlinear editors, quality inspectors and teachers for interaction on the micro-teaching platform. The clear division of labor within the team can not only help its members carry out their duties efficiently, but also make the micro-lecture work more professional.

\section{Development of Reusable Micro-lectures}

The Open Educational Resources (OER) movement is driving a profound change in the field of higher education. "Knowledge walls" are disappearing, education restrictions brought by space, economy, population and other factors continue to reduce. In a word, the opening and sharing of educational resources has become an irresistible trend. The construction of college English micro-lecture resources must conform to this historical trend, so as to promote the coconstruction and sharing of education resources and the sustainable development of micro-teaching. The coconstruction and sharing of micro-lectures can effectively avoid repetitive production and waste of resources and bring more interconnected and complementary works. This sharing helps micro-lecture producers get access to various types of micro-lectures from different sources and periods for further processing. The full use of micro-lectures makes it possible to achieve college English education with high quality and low cost. Furthermore, it can effectively promote the exchange between micro-lecture makers and encourage more learners to share.

In addition, the problem of valuing construction and neglecting application should be avoided. Due to the promotion of many competitions, a large number of college English micro-lectures emerged, but many works were not made for the purpose of application but for competition. The theory of diminishing marginal effect tells us that the benefit of resource application does not lie in quantity, or diversity, but in that whether a maximum validity can be achieved. That is to say whether it is able to meet the user's demand for appropriate use and timely use [4].

College English micro-lecture development should be based on the benefit of English teaching and learning, focusing on its reusability to produce a series of systematic micro-courses. Therefore, the use of information technology and photography skills in micro-lecture making should be guided by the principle of adequate amount and appropriate tempo, because teaching and learning should always be put in the first place.

\section{Combined Use with MOOC and Flipped Class}

Micro-lecture plays an indispensable role in MOOC and flipped classroom teaching as they are easy to be reused and shared. The combination of micro-lecture with MOOC and flipped classroom teaching is undoubtedly a direction of college English teaching reform.

MOOC is virtually a micro-teaching way of education with video resources made up mostly of short videos of a few minutes. It is not only conducive to the students to get systematic learning by subjects, but also convenient for their fragment learning anytime and anywhere. The construction of college English micro-lectures should be guided by an overall planning and take large-scale open learning as its goal. At the same time, micro-lecture resource should highlight its convenience for interactive communication, as interactive communication is a major feature of MOOC.

Flipped classroom teaching has become a popular teaching mode in college English in recent years. It emphasizes the students' subjectivity and interaction, that is, to inspire and stimulate the students' initiative and motive, improving their abilities to learn and internalize knowledge they've learned through interaction.

\section{E. Standardizing Evaluation Criteria}

Evaluation criterion is an important guide for the production of micro-lectures, so the establishment of such criterion is of great significance. The evaluation criteria of the micro-lectures in China mainly come from those of various micro-lecture competitions, such as the criteria set by the Ministry of Education Network Center, by the Ministry 
of Education Management Information Center and by the Discipline of Chinese Higher Education. Although the three sets of standards emphasize different aspects, they evaluate on much the same points. To be more specific, selection of topics, materials, technology, teaching and effectiveness are all treated as the main factors for evaluation. But different evaluation criteria should be made for different subject. For the evaluation of foreign language micro-lectures, the competitions focus more on topics, materials and design. The lecturer's language, however, is neglected.

Further exploration and discussion are needed to improve and perfect these criteria. For example, are competition standards also applicable for the evaluation of micro-lectures made for practical teaching? Competition standards focus on a single micro-lecture, but the development goal of microlectures for routine teaching is a series of micro-lectures. The evaluation criteria of the two are obviously different. In addition, as a means of foreign language teaching, the demonstrative effect of the lecturer's use of the language must not be ignored. So the lecturer's language should also be included as an important aspect in evaluation.

\section{CONCLUSION}

The development of information technology has given rise to a new learning mode: micro-lecture. The students today are Digital Natives who are born and living in a world of internet, and the digital life style is their way of life. On the contrary, the majority of the teachers are so called Digital Immigrants, who often feel powerless in the face of massive digital information, the rapid development of technology and digital products. To avoid the embarrassment of competing with mobile phones to attract the students in class, college English teachers must update their concepts about teaching, apply information technology to their teaching and actively explore the teaching law in the information age.

\section{REFERENCES}

[1] LeRoy A. McGrew, "A 60-Second Course in Organic Chemistry,” [J]. Journal of Chemistry Education, 1993,(70), pp. 543-544.

[2] Huang J.J.,Guo S.Q., "On the Design and Development of Micro Curriculum,” [J]. Modern Educational Technology, 2013, (5), pp. 3135 .

[3] Chang Z.H., "Micro-lecture: a New Type of Learning Resources," [J]. China Educational Technology \& Equipment, 2013, (20), pp. 50-51.

[4] Hu T.S., "Micro-lecture: The new trend of Development of Regional Education Information Resources," [J]. E-education Research, 2011, (10), pp. 61-65 